\title{
The adder (Vipera berus) in Southern Altay Mountains: Population characteristics, distribution, morphology and phylogenetic position
}

\author{
Shaopeng Cui ${ }^{1,2}$, Xiao Luo ${ }^{1,2}$, Daiqiang Chen ${ }^{1,2}$, Jizhou Sun ${ }^{3}$, Hongjun Chu ${ }^{4,5}$, Chunwang Li ${ }^{\text {Corresp., }}{ }^{1,2}$, \\ Zhigang Jiang Corresp. 1, 2 \\ ${ }^{1}$ Key Laboratory of Animal Ecology and Conservation Biology, Institute of Zoology, Chinese Academy of Sciences, Beijing, China \\ 2 University of Chinese Academy of Sciences, Beijing, China \\ 3 Kanas National Nature Reserve, Buerjin, Urumqi, China \\ 4 College of Resources and Environment Sciences, Xinjiang University, Urumqi, China \\ 5 Altay Management Station, Mt. Kalamaili Ungulate Nature Reserve, Altay, China \\ Corresponding Authors: Chunwang Li, Zhigang Jiang \\ Email address: licw@ioz.ac.cn, jiangzg@ioz.ac.cn
}

As the most widely distributed snake in Eurasia, the adder (Vipera berus) has been extensively investigated in Europe but poorly understood in Asia. The Southern Altay Mountains represent the adder's southern distribution limit in Central Asia, whereas its population status has never been assessed. We conducted, for the first time, field surveys for the adder at two areas of Southern Altay Mountains using a combination of line transects and random searches. We also described the morphological characteristics of the collected specimens and conducted analyses of external morphology and molecular phylogeny. The results showed that the adder distributed in both survey sites and we recorded a total of 34 sightings. In Kanas river valley, the estimated encounter rate over a total of $137 \mathrm{~km}$ transects was $0.15 \pm 0.05$ sightings $/ \mathrm{km}$. The occurrence of melanism was only $17 \%$. The small size was typical for the adders in Southern Altay Mountains in contrast to other geographic populations of the nominate subspecies. A phylogenetic tree obtained by Bayesian Inference based on DNA sequences of the mitochondrial cytochrome $b$ (1023 bp) grouped them within the Northern clade of the species but failed to separate them from the subspecies $V$. b. sachalinensis. Our discovery extends the distribution range of $V$. berus and provides a basis for further researches. We discuss the hypothesis that the adder expands its distribution border to the southwest along the mountains' elevation gradient, but the population abundance declines gradually due to a drying climate. 
1 The adder (Vipera berus) in Southern Altay Mountains:

2 Population characteristics, distribution, morphology and

3 phylogenetic position

4 Shaopeng Cui ${ }^{1,2}$, Xiao Luo ${ }^{1,2}$, Daiqiang Chen ${ }^{1,2}$, Jizhou Sun ${ }^{3}$, Hongjun Chu ${ }^{4,5}$, Chunwang $\mathrm{Li}^{1,2 *}$, Zhigang

5 Jiang ${ }^{1,2 *}$

$6{ }^{1}$ Key Laboratory of Animal Ecology and Conservation Biology, Institute of Zoology, Chinese Academy of

7 Sciences, Beijing, China

82 University of Chinese Academy of Sciences, Beijing, China

$9{ }^{3}$ Kanas National Nature Reserve, Buerjin, Xinjiang, China

${ }^{4}$ College of Resources and Environment Sciences, Xinjiang University, Urumqi, Xinjiang, China

${ }^{5}$ Altay Management Station, Mt. Kalamaili Ungulate Nature Reserve, Altay, Xinjiang, China

${ }^{*}$ Co-corresponding Author:

Chunwang Li, licw@ioz.ac.cn

Zhigang Jiang, jiangzg@ioz.ac.cn 
25 Abstract

26

27

As the most widely distributed snake in Eurasia, the adder (Vipera berus) has been extensively investigated in Europe but poorly understood in Asia. The Southern Altay Mountains represent the adder's southern distribution limit in Central Asia, whereas its population status has never been assessed. We conducted, for the first time, field surveys for the adder at two areas of Southern Altay Mountains using a combination of line transects and random searches. We also described the morphological characteristics of the collected specimens and conducted analyses of external morphology and molecular phylogeny. The results showed that the adder distributed in both survey sites and we recorded a total of 34 sightings. In Kanas river valley, the estimated encounter rate over a total of $137 \mathrm{~km}$ transects was $0.15 \pm 0.05$ sightings $/ \mathrm{km}$. The occurrence of melanism was only $17 \%$. The small size was typical for the adders in Southern Altay Mountains in contrast to other geographic populations of the nominate subspecies. A phylogenetic tree obtained by Bayesian Inference based on DNA sequences of the mitochondrial cytochrome $b$ (1023 bp) grouped them within the Northern clade of the species but failed to separate them from the subspecies $V$. b. sachalinensis. Our discovery extends the distribution range of $V$. berus and provides a basis for further researches. We discuss the hypothesis that the adder expands its distribution border to the southwest along the mountains' elevation gradient, but the population abundance declines gradually due to a drying climate.

\section{Introduction}


As the most widely distributed terrestrial snake on the planet, the adder, Vipera berus

46

47

48

Linnaeus, 1758, occupies nearly one-third of the Eurasian continent (Saint Girons, 1980; Gasc et al., 1997). Its range extends from Scotland ( $\left.6^{\circ} \mathrm{W}\right)$ east to Sakhalin Island of the Russian Far East $\left(143^{\circ} \mathrm{E}\right)$, and from Greece $\left(42^{\circ} \mathrm{N}\right)$ north to northern Fennoscandia $\left(69^{\circ} \mathrm{N}\right)$ (Nilson, Andrén \& Szyndlar, 1994; Sillero et al., 2014). Three subspecies are generally recognized: the nominate subspecies $V$. $b$. berus is found in most of the distribution range, $V$. b. sachalinensis is restricted to East Asia, and $V . b$. bosniensis occurs on the Balkan Peninsula, though some authors also consider Vipera nikolskii as a subspecies of the adder according to the biological species concept (Milto \& Zinenko, 2005; Zinenko, Țurcanu \& Strugariu, 2010). The species inhabits diverse biotopes throughout northern temperate regions in various altitude ranges from sea level in the north up to the altitude of $2600 \mathrm{~m}$ in the south (Gasc et al., 1997). Extensive studies on the adder have been published, for example on intraspecific taxonomy, mechanism of thermal melanism, and phylogeography (Nilson, Andrén \& Szyndlar, 1994; Ursenbacher et al., 2006; ClusellaTrullas, van Wyk \& Spotila, 2007; Joger et al., 2007). However, most studies were concentrated on the European part of its distribution range; little is known from other regions, especially Central Asia. For example, in Mongolia, the adder has so far been found in fewer than 5 locations and the last study in northern Mongolia was dated back to 100 years ago (Terbish et al., 2006). A potential bias may exist in the ecological knowledge of the species, which might impede drawing generalizations, particularly when considering the geographical variation expressed throughout the entire range of the adder.

The southern boundary of taiga coniferous forests in Southern Altay Mountains is the 
66 southern distribution limit of the adder in Central Asia (Bannikov et al., 1977). Meanwhile, the

67 easternmost distribution of steppe viper $V$. renardi extends to the northwest foothills located

68

among Altay, Saur and Tarbagatai mountains (Nilson \& Andrén, 2001; Gvoždík et al., 2012), where Tuniyev, Nilson \& Andrén (2010) found a new species, $V$. altaica, which was closely related to but distinct from the parapatric $V$. renardi (see Fig. 1). The Mountains have also long been regarded as a transitional zone between the Siberian taiga forest and Central Asia steppe ecosystems, which are sensitive to climate change (Xu et al., 2015). The range limit of a species is its evolutionary response to the ecological constraints (Holt \& Keitt, 2005). Therefore, studying the distribution of the adder in Southern Altay Mountains will help to understand the distribution patterns of reptiles and the influence of climate change on the boundary between the Euro-Siberian Subrealm and the Central Asia Subrealm (Zhang, 1999; Ravkin, Bogomolova \& Chesnokova, 2010; Zhou \& Shi, 2015). Comparative morphology and molecular phylogeny analyses for adders in Altay could shed light on its adaptation along the gradients of environment and the divergence and colonization history of the genus Vipera.

Recent phylogeographic studies have revealed that some widespread species are actually composed of multiple taxa, e.g. North American rat snake (Burbrink, Lawson \& Slowinski, 2000), common kingsnake (Alexander Pyron \& Burbrink, 2009), and steppe viper (Ferchaud et al., 2012). Although the published cladograms putatively represent all recognized taxa of the adder, it is possible that yet undiscovered taxa exist due to incomplete sampling (Ursenbacher et al., 2006). The taxonomy of adder population in Southern Altay Mountains is unclear and its geographic distribution remains unknown (Bannikov et al., 1977; Zhao \& Adler, 1993; Zhao, 
87 2006). So far, only three specimens (2 adults and 1 juvenile) have previously been recorded in

88 China (Zhao, Huang \& Zong, 1998). Indeed, the entire Altay Mountains are regarded as the part

89 of the distribution range of the adder but until now no detailed investigation has been conducted

90 in the region.

91 In this study, we tried to obtain new data on geographic distribution, population characteristics, morphology and phylogenetic position of the poorly-known adder populations in Southern Altay Mountains. We collected specimens in the field and described the geographical variation in body dimensions, scalation and color pattern. We furthermore conducted phylogenetic analyses based on mitochondrial cytochrome $b$ gene sequences to confirm the systematic position of the adder populations in the region.

\section{$97 \quad$ Materials \& methods}

\section{Ethics Statement}

This study was reviewed and approved by the Ethical Committee of the Institute of Zoology, Chinese Academy of Sciences (Permit Number IOZ14060). All procedures performed in this study were in accordance with the instructions and permission of the Ethical Committee and the Chinese Wildlife Management Authority.

Study area and field surveys

The study was conducted in the Southern Altay Mountains in the region bordering Russia,

Mongolia and Kazakhstan. The elevation ranges from approximately $1000 \mathrm{~m}$ in river valleys to $4374 \mathrm{~m}$ at the summit. The study area has a typical temperate continental climate with short, cool 
107

108

109

110

111

112

113

114

115

116

117

118

119

120

121

122

123

124

125

126

127

summers and long, cold winters. The forest type is the boreal coniferous forests and the main tree

species include Siberian spruce Picea obovata, Siberian larch Larix sibirica, Siberian pine Pinus

sibirica, Siberian fir Abies sibirica, European aspen Populus tremula, and birch Betula pendula.

The natural vegetation on the mountains varies with different altitude and aspect. The following

vegetation belts can be recognized: coniferous forest, broad-leaved forest, mixed forest, shrubby

steppe, subalpine shrub and meadow, alpine meadow, and nival belt.

We chose the Kanas river valley as the main survey area while we conducted a

complementary research in Daxiaodonggou Forested Area (Fig. 1). The Kanas river valley in the northwest of Southern Altay Mountains is relatively close to the distribution range of the adder;

the valley is strictly protected by three protection stations within the core area of Kanas National

Nature Reserve. Daxiaodonggou Forested Area is located in the northwest-central part of the

mountains, about 130 kilometers from the main survey site. A combination of 20 line transects

and random searches were conducted to investigate the abundance and distribution of adders in

the two survey areas (Fig. 1). In Kanas river valley, we set up 6 line transects around each

protection station (a total of 18 transects), which were spaced 1 to 2 kilometers apart to assist

spatial independence of snake observations. Transects began at the east of Kanas Lake and ended

on the edge of Bai Lake. Each transect began where the forest or steppe edge met the river,

aiming to representatively sample all habitats and exposures. The length and direction of

transects were varied due to safety hazards from the terrain or vegetation (see Supplemental

Data). To investigate whether the adder was distributed in Daxiaodonggou Forested Area, we

arbitrarily established 2 line transects to extend between the valley and hillside. Opportunistic 
128 sightings (e.g. travelling between protection stations along the riding track) were also recorded 129 during fieldwork.

130 Except during rainy or foggy weather, we surveyed each transect at least twice between

131 10:00 and 19:00 hours during a 170-day period (21 June to 17 September 2014, 21 June to 9 September 2015, see Supplemental Data) by walking slowly (ca. $1-1.5 \mathrm{~km} / \mathrm{h}$ ). We searched mainly in open ground and under vegetation for adders. On all 18 line transects in Kanas river valley, we identified and recorded adders for the forward journeys only, to avoid counting the same individuals twice. At least 10 days were allowed between successive surveys on the same transect.

To standardize sampling, we used a simple encounter rate (number of sightings per km walked $\pm \mathrm{SE}$ ) as a proxy for relative species abundance. We could not distinguish black individuals between sexes based on the sexual dichromatism in the dorsal pattern due to melanism, so we did not determine the sex ratio of the targeted adder population in this study.

We collected 9 specimens ( 3 males and 6 females) in Kanas river valley. We captured one adder from Daxiaodonggou Forested Area to determine the occurrence of the adder, and then released it at the point of capture. All the collected specimens were preserved in 95 or $100 \%$ ethanol and deposited in the herpetological collections of the Institute of Zoology, Chinese Academy of

Sciences, Beijing, China. Collection information and voucher numbers are shown in Supplemental Data.

\section{Morphological description and comparison}

For the collected specimens, we described the morphological features in terms of body 
149 dimensions, scalation and color pattern. The measurements of eight characteristics traditionally

150 used in Vipera systematics were recorded: apicals (refers to the apical scales, similarly

151 hereinafter for the other different scales), supralabials, sublabials, circumoculars, crowns, loreals,

152 ventrals, and subcaudals.

153 We also extracted the corresponding morphological data of related taxa from the available

154 literature: $V$. b. berus from Northwestern, Southwestern and Eastern Europe (Nilson, Andrén \&

155 Szyndlar, 1994; Milto \& Zinenko, 2005); V. b. sachalinensis from Northern Korea and Sakhalin

156 (Nilson, Andrén \& Szyndlar, 1994); V. b. bosniensis from Balkan (Nilson, Andrén \& Szyndlar,

157 1994); V. altaica from Eastern Kazakhstan (Tuniyev, Nilson \& Andrén, 2010); V. renardi from

158 the eastern lowland of Central Asia (Nilson \& Andrén, 2001; Tuniyev, Nilson \& Andrén, 2010).

159 Considering the sexual dimorphism present in pholidosis characteristics, both sexes were studied

160 separately for ventrals and subcaudals.

161 We tested whether there were significant differences in the number of scales among different taxa from different geographical regions using a one-way analysis of variance (ANOVA), and we also performed a post-hoc Student-Newman-Keuls (SNK) multiple comparison tests to compare selected pairs of data. If data did not meet the criteria for homogeneity of variance, two-tailed unequal variance t-test followed by Bonferroni correction was performed (Ruxton, 2006). All statistical approaches were completed using R v3.1.2 (R

167 Core Team, 2013). $P<0.05$ was regarded as statistically significant. However, because of the small sample size, we did not conduct statistical analyses on the ventrals and subcaudals from different sexes. 
170

171

172

173

174

175

176

177

178

179

180

181

182

183

184

185

186

187

188

189

190

\section{Molecular phylogenetic analyses}

Genomic DNA was extracted from tissue samples of each specimen using TIANamp

Genomic DNA Kit (Tiangen Biotech, Beijing, China), following the manufacturer's instructions.

We amplified and sequenced partial mitochondrial cytochrome $b$ (Cyt $b$ ) gene with the primers

(Ursenbacher et al., 2006):

L14724Vb (5'-GATCTGAAAAACCACCGTTG-3'),

H15548Vb (5'-AATAGAAAGTATCATTCTGGTTTAAT-3'),

L15162Vb (5'-CTCCCATGAGGACAAATATC-3'),

and H15914Vb (5'-CCAGCTTTGGTTTACAAGAAC-3').

Polymerase chain reaction (PCR) was performed in a $40 \mu \mathrm{L}$ final volume with $4 \mu \mathrm{L}$ DNA

template, $20 \mu \mathrm{L}$ of Ex Taq polymerase (RR001A, TaKaRa), $4 \mu \mathrm{L}(20 \mathrm{mmol} / \mathrm{L})$ of each of the

two primers and $8 \mu \mathrm{L}$ of double distilled water. PCR programs to amplify the two parts of Cyt $b$

started with a cycle of denaturing at $94{ }^{\circ} \mathrm{C}$ for $10 \mathrm{~min}$, followed by 35 cycle of $94{ }^{\circ} \mathrm{C}$ for $45 \mathrm{~s}, 50$

${ }^{\circ} \mathrm{C}$ for $60 \mathrm{~s}$, and $72{ }^{\circ} \mathrm{C}$ for $90 \mathrm{~s}$, and a final extension at $72{ }^{\circ} \mathrm{C}$ for $10 \mathrm{~min}$. PCR products were

sequenced by Sino Geno Max (Beijing, China), using ABI 3730XL sequencers. Sequences were

deposited in GenBank (accession numbers KU942378 and KX345249 to KX345256).

Cyt $b$ sequences were visualized with MEGA 6.0 (Tamura et al., 2013), aligned with the

ClustalW option included in this software and double-checked by eyes (Larkin et al., 2007). The

number of haplotypes and polymorphic sites was obtained with DnaSP v5.0 (Librado \& Rozas,

2009). Only one haplotype was recognized in all 9 samples and compared to other 33 sequences

downloaded from GenBank. We used V. seoanei, V. altaica, and V. renardi as outgroups (see 
191 Supplemental Table S1). Sequence differences were calculated using MEGA 6.0 based on

192 Kimura's two-parameter model (Tamura et al., 2013). The best-fit model of nucleotide

193 substitution was calculated by the Akaike Information Criterion (AIC) approach in Modeltest

194 v3.7 (Posada \& Crandall, 1998). Then, we conducted the Bayesian inference (BI) of phylogeny

195 with MrBayes v3.2 (Ronquist \& Huelsenbeck, 2003) using the best-fitted model. Four chains

196 were run simultaneously and each Markov chain was started from a random tree and run for

$1971 \times 10^{7}$ cycles, with sampling every 1000 th cycle. The convergence was estimated by measuring

198 the standard deviation of the split frequency among parallel chains. Chains were considered to

199 have converged when the average split frequency was lower than 0.01 . The initial $25 \%$ trees

200 were discarded as burn-in values.

201 Results

202 Field surveys

203 In the two survey sites, we recorded a total of 34 sightings of adders, of which 31 were from

204 Kanas river valley (17 and 14 in 2014 and 2015, respectively) and 3 from Daxiaodonggou

205 Forested Area. There were 29 sightings of subadults and adults (henceforth adults), 1 juvenile

206 trampled by a horse with body length of $270 \mathrm{~mm}, 1$ newborn in Kanas valley, and 3 adults in

207 Daxiaodonggou Forested Area. However, we did not mark the encountered adders in the field

208 survey, so the same individual was likely counted multiple times. In Kanas river valley, a total of

$209105 \mathrm{~km}$ of line transects was surveyed and the overall encounter rate was $0.15 \pm 0.05$

210 sightings $/ \mathrm{km}$. Melanistic adders were relatively rare with only $17 \%(\mathrm{n}=5)$ of the total number of 
211 adults. The adders were found mostly in coniferous forest (18 out of 34 sightings, 53\%) at

212 elevations ranging from $1200 \mathrm{~m}$ to $2300 \mathrm{~m}$ (see Supplemental Data). There was only one snake

213 species (i.e. . berus) observed in Kanas valley which is about 80 kilometers from the nearest

214 population of $V$. renardi (Fig. 1), but Elaphe dione and Coluber spinalis occurred in

215 Daxiaodonggou Forested Area.

216 Morphological characteristics

217 The largest specimen (voucher number IOZ015018) examined by us was a female

218 measuring $510 \mathrm{~mm}$ in total length and $54 \mathrm{~mm}$ from the posterior margin of cloacal opening to the

219 tip of tail (tail length); the latter was equal to $10.6 \%$ of body length. The largest male

220 (IOZ015020) had a total length of $490 \mathrm{~mm}$, including $68 \mathrm{~mm}$ tail length (13.9\% of total length).

221 The males averaged at a total length of $449.3 \pm 21.5 \mathrm{~mm}(\mathrm{n}=3)$ while the mean length of the

222 females was $487.8 \pm 6.7 \mathrm{~mm}(\mathrm{n}=5)$. Some morphological characteristics were identical in all

223 collected specimens: 2 large supraoculars and 1 large frontal plate on top of head, parietals

224 divided, 1 canthal and 1 supranasal scale on each canthus rostralis, 1 scale between nasal and

225 rostral on each side, 2 apicals in contact with rostral, and a single row of scales between

226 supralabials and eye. However, individual variation was evident in some scalation characters as

227 follows: 4 to 10 intercanthals, 5 to 14 intersupraoculars, 2 to 5 loreals on each side, normally 9 to

22810 supralabials and 9 to 11 sublabials on each side, and 1 to 3 preventrals. The eyes were

229 surrounded by 18 to 25 circumoculars; the rostral bordered by 2 supralabials. 144 to 150 ventrals

230 and 31 to 38 subcaudals in females, 140 to 146 ventrals and 37 to 40 subcaudals in males, all

231 subcaudals in double rows, 20 to 21 rows of dorsal scales around midbody. Detailed 
232 morphological data of each specimen with the corresponding voucher number can be found in 233 the Supplemental Raw Data.

234 Dorsal pattern consisted of a continuous winding zig-zag band in females and males. Lateral 235 body blotches were present except in melanistic males, ventral side black, the tip of tail pigmented by yellow or orange. Preoculars and frontal were separated from nasal and supraoculars on each side, respectively. Females, whether or not they were melanistic, had light dots on ventrals and reddish-brown colored throat. Non-melanistic specimens had two dark oblique bands on the dorsal head and light spots on some supralabials, apicals, supranasals, and supraoculars.

Sexual dichromatism in the dorsal pattern was well expressed. All non-melanistic females had a dark brown zig-zag band on light brown background. Compared with that, males showed a much higher color contrast in dorsal pigmentation, usually with black zig-zag turns and greyish ground color.

\section{Morphological comparison}

The mean values and standard errors of morphological characteristics, which were

calculated for 9 specimens in this study and extracted from literature for the samples from other regions, are shown in Fig. 2 and Table 1. The specimens examined by us were distinguishable from $V$. altaica and $V$. renardi in the character of apicals, crowns, and loreals (all $P<0.05$ ). At subspecies level, the results demonstrated geographical variation in morphological characteristics.

Taken as a whole, the adders from Southern Altay Mountains exhibited a tendency toward 
253 apicals, sublabials and crowns, and bosniensis in sublabials and loreals (all $P<0.05)$. When

254 compared with other specific populations of the nominate subspecies from different regions, our

255 materials only showed a difference with Northwestern Europe and Southwestern Europe

256 populations in supralabials and crowns, respectively; they had no difference with adders from

257 Eastern Europe. In addition, the maximal number of crown shields of head and minimal number

258 of loreals and sublabials were recorded in our specimens.

259 Males and females expressed sexual dimorphism in the number of ventrals and subcaudals

260 (Table 1). The adder from Southern Altay Mountains was similar to $V . b$. berus populations from

261 Northwestern Europe and Eastern Europe and $V . b$. bosniensis population from Balkan in both

262 female and male values; they showed much increased number of subcaudals compared with the

263 nominate subspecies in Southwestern Europe and sachalinensis subspecies. Our samples also

264 differed from $V$. b. sachalinensis in female's ventrals. $V$. altaica resembled our specimens in

265 ventrals (the average number is 145.9 in $V$. altaica, Tuniyev, Nilson \& Andrén (2010) pooled

266 both sexes when analyzing morphological data), but it had much lower average number of

267 subcaudals especially in female.

268 Molecular phylogenetic analyses

The alignment of the mtDNA Cyt $b(1023 \mathrm{bp})$ of the adders contained 119 variable sites and

61 parsimony informative sites. All samples in our study shared the same haplotype, which was

identical to that from Perm in Russia (see Supplemental Data).

The Bayesian phylogenetic tree clearly separated three major lineages of the adder, the

Italian clade, Balkan clade and Northern clade, each receiving high statistical support (Fig. 3). 
274 The three currently accepted subspecies did not represent distinct genetic lineages; only the

275 Balkan clade conformed to the bosniensis subspecies. The majority of haplotypes of $V . b$. berus

276 grouped within the Northern clade while the haplotypes of the populations from Italy and

277 adjacent areas were clustered together within the Italian clade. The adder from Southern Altay

278 Mountains was grouped into the Northern clade and clearly separated from the other two clades.

279 Moreover, the BI reconstruction was not able to separate the sachalinensis subspecies from the

280 nominate subspecies.

281 The Kimura two-parameter distances among all Vipera berus were displayed in Table 2.

282 The genetic distance between the Southern Altay group and the Northern clade was $0.003 \pm$

283 0.001, which was lower than any other pairwise distances. However, a low degree of genetic

284 differentiation $(0.005 \pm 0.002)$ was also observed between our specimens and the sachalinensis

285 subspecies.

\section{Discussion}

The adders observed during line transect surveys represent an estimated encounter rate of

0.15 sightings per $\mathrm{km}$ in Southern Altay Mountains. The relatively low number of sightings $(\mathrm{n}=$

13) may reduce the reliability of abundance estimates since the minimum sample size of 40

(Buckland et al., 2001) has not been reached. However, such a number may be difficult to

achieve due to the scarcity of adders (Terbish, Munkhbayar \& Munkhbaatar, 2006), even if

intensive surveys are considered (in this study the riding track was surveyed many times during

fieldwork). Unfortunately, as there is no previous report on the abundance of adders in Southern 
294 Altay Mountains (only few reports of its occurrence, Zhao \& Adler, 1993; Zhao, Huang \& Zong, 295 1998), we cannot compare our results with others.

The occurrence of melanism is low in the studied adder population, among which only $17 \%$

297

298

299

300

301

302

303

304

305

306

307

308

309

310

311

312

313

314

of all observed adults are melanistic. This ratio differs from most results obtained from other geographic populations in previous studies (e.g. $47 \%$ in southwest Sweden, Andrén \& Nilson, $1981 ; 49 \%$ in the Carnic Alps, Luiselli, 1992; 47\% in the Swiss Alps, Monney, Luiselli \& Capula, 1995; but 16\% in the Northern Romanian Carpathians, Strugariu \& Zamfirescu, 2011). The color of ectothermic vertebrates plays a significant role in thermoregulation processes (Clusella-Trullas, van Wyk \& Spotila, 2007). The thermal melanism hypothesis posits that melanistic individuals have benefits in cool habitats because, with low skin reflectance, they heat up faster and reach higher equilibrium temperatures than normal individuals (Clusella-Trullas, van Wyk \& Spotila, 2007). This hypothesis has been widely studied in ectothermic species, especially the color-polymorphic adder (Andrén \& Nilson, 1981) and Vipera aspis (Castella et al., 2013). Thus, considering the southernmost marginal location of our study area in the adder's distribution range of Central Asia, the observed low occurrence of melanism may be a result of a much warmer climate. However, as Strugariu \& Zamfirescu (2011) argued, such a speculation may only provide a partial explanation, because the Kanas river valley has a typical continental climate with an average summer temperature of $15.0^{\circ} \mathrm{C}$, slightly colder than both the Northern Romanian Carpathians and southwest Sweden (summer average temperature of $15.4{ }^{\circ} \mathrm{C}$ and 16.1 ${ }^{\circ} \mathrm{C}$, respectively; Hijmans et al., 2005). Andrén \& Nilson (1981) argued that the presence of melanism might depend on the trade-off between thermoregulatory benefit and predation cost. 
The adder exhibits a low level of geographically correlated morphological variation,

especially the nominate subspecies with a rather homogeneous scalation characteristics (Fig. 2).

317 However, the mean length of the adult adder (males and females averaged at $44.93 \mathrm{~cm}$ and 48.78

$\mathrm{cm}$ respectively) in Southern Altay Mountains is smallest among those presented by other similar

studies (around $56 \mathrm{~cm}$ and $62 \mathrm{~cm}$ in the eastern Swedish islands, Forsman and Âs, 1987; $55 \mathrm{~cm}$

and $65 \mathrm{~cm}$ in northern England, Phelps, 2004; $55 \mathrm{~cm}$ and $62 \mathrm{~cm}$ in southwestern Sweden, Andrén

and Nilson, 1981; $47 \mathrm{~cm}$ and $52 \mathrm{~cm}$ in the Swiss Alps, Monney, Luiselli \& Capula, 1995; 44.98

$\mathrm{cm}$ and $51.87 \mathrm{~cm}$ in the northern Romanian Carpathians, Strugariu \& Zamfirescu, 2011). This

relatively atypical size, together with the higher number of crowns and subcaudals (only in

females) and lower number of loreals and sublabials, could be considered autapomorphic traits of

the adder on Southern Altay Mountains at the southern distribution margin. It is generally

accepted that the geographical variation of external traits results from historical (i.e. phylogenetic)

and environmental (i.e. adaptive) factors, first by population isolation in geographic refuges and

further by local adaptation to divergent environments (Thorpe et al., 1991; Malhotra \& Thorpe,

1997; Santos et al., 2014). For example, many studies have demonstrated that the number of

ventral scales in snakes is strongly related to the geographic origin (Dohm \& Garland, 1993;

Fornasiero et al., 2007), but also that the thermal condition can influence the within-population

ventral scale variation during embryogenesis (Osgood, 1978; Lourdais et al., 2004).

preferred over the labile characteristics, as color patterns do in the North American rat snake 
336 for the subspecies bosniensis, including two subocular scale rows, high percent of specimens

337 with interrupted zig-zag pattern, and a higher row number of dorsal scales around midbody. For

338 the subspecies sachalinensis, two characteristics were previously proposed as diagnostic by

339 Nilson, Andrén \& Szyndlar (1994): frontal in contact with supraoculars and upper preocular in

340 contact with nasal. Our specimens did not show these special characteristics of the two

341 subspecies. Therefore, although the applicability of these characteristics for determination is still

342 questioned in certain regions (e.g. Zhao, Huang \& Zong, 1998; Zhao, 2006), they can be called

"working" in Southern Altay Mountains. This result could allow an expected conclusion that, on

a morphological basis, the adder in Southern Altay Mountains differs from $V$. b. bosniensis and $V$.

b. sachalinensis and belongs to $V . b$. berus. It is well accorded with the real situation that the

survey area of Kanas river valley is located near the distribution range of the nominate

subspecies in the border region of Russia and Kazakhstan, and also covered by a same Siberian taiga habitat (Zhang, 1999; Ravkin, Bogomolova \& Chesnokova, 2010).

The adder population from Southern Altay Mountains was grouped into the Northern clade together with those populations from Eastern Europe to Sakhalin Island of the Russian Far East across the adders' range (Fig. 3). Despite the southernmost marginal distribution in Central Asia, phylogenetically the population was not classified into a separate group, supporting the presented phylogenetic relationships (Ursenbacher et al., 2006). Our samples were clearly separated from the Balkan clade and Italian clade, in line with the morphological results. The few morphological similarities between them (e.g. in supralabials) may be caused by either parallel evolution (parallelism) or ancestral characteristics (symplesiomorphy) (Nilson, Andrén \& Szyndlar, 1994; 
357 Ursenbacher et al., 2006). The low degree of genetic differentiation between adders from

358 Southern Altay Mountains and the sachalinensis subspecies indicates complex recolonization

359 dynamics of the Eurasia continent by $V$. berus (Ursenbacher et al., 2006). The mitochondrial

360 DNA alone may be less informative for distinguishing the taxon sachalinensis in DNA

361 sequence-based methods (Ursenbacher et al., 2006; Wares, 2014). The origin and splitting

362 history of $V$. sachalinensis are yet poorly understood, neither does the subspecific boundary

363 (Bannikov et al., 1977), partly due to scanty field work towards this subspecies.

$V$. altaica lives in lowland and foothill habitats in the altitude range of 200 to $1200 \mathrm{~m}$, but is

characterized by having the morphological characteristics typical for montane taxa. Its range

occurs at the parapatric boundary of $V$. renardi and $V$. berus (Tuniyev et al., 2010). One possible

condition is that this doubtful species is an assemblage of hybrids between $V$. renardi and $V$.

berus. However, we did not find $V$. altaica expressed intermediate morphologies and its special

features compared with eastern lowland $V$. renardi, including smallest size (maximum total

length is $38.8 \mathrm{~cm}$ for males, and $39.9 \mathrm{~cm}$ for females), non-bilineate dorsal pattern, white belly

and no suture on the supralabials, also differed from those of our specimens. Furthermore, the

number of apicals is a key discriminator as the adder has more apicals than the steppe viper,

while all altaica samples have only one apical (Tuniyev et al., 2010). Also, there are no

melanistic individuals observed in the taxon altaica. Phylogenetic analyses revealed that $V$.

altaica was grouped with $V$. renardi, and no mtDNA introgression detected in this study. To

377 Therefore, as has been previously suggested, $V$. altaica may be a relict species (Tuniyev et al., 
378

379

380

381

382

383

384

385

386

387

388

389

390

391

392

393

394

395

396

397

398

2010; Zinenko et al., 2015).

The early accounts of Zhao, Huang \& Zong (1998) reported finds of the adder in Fuhai County about 70 kilometers southeast of Daxiaodonggou Forested Area, indicating that the adder expands its distribution from northwest to southeast along the elevation gradient in the Southern

Altay Mountains. However, the eastern mountains of the Junggar basin create a barrier effect that restricts the eastward penetration of Atlantic westerlies (Fig. 1). This factor, together with the influence of arid climate in Mongolia, leads to an increasing continentality and decreasing precipitation (Wei et al., 2003). The drying climate changes the structure and composition of the vegetation, so it is reasonable to suppose that the population abundance of adders declines gradually towards the southeast along the Mountains. The dominant role of the adder may be replaced by other snake species (e.g. Elaphe dione and Coluber spinalis), as described in this study. However, the existing data concerning the adder over the Southern Altay Mountains was too scarce to corroborate the hypothesis. The further research can explore the geographic range limit of the adder by investigating its population dynamics from Daxiaodonggou Forested Area southeastward along the mountains.

Despite occupying a wide distribution, the adder is often found restricted to highly fragmented populations and isolated mountainous relicts (Schiemenz, 1995; Sillero et al., 2014). Human activities have resulted in a massive reduction in population size in certain regions, such as Smygehuk in southern Sweden where, due to agricultural activities, an adder population is clearly separated from neighboring populations varying in size from less than 50 to more than 250 adult individuals (Madsen, Stille \& Shine, 1996 and references therein). Our study highlights 
399 a fundamental issue regarding an assessment of the conservation status of the poorly-known

400 species in Central Asia. The adder is also poorly studied but believed to be experiencing a

401 decline in habitat quality and extent in Mongolia (Terbish et al., 2006). The last study in northern

402 Mongolia dates from 100 years ago. Terbish et al. (2006) categorized the adder as Vulnerable

403 according to IUCN Red List criteria at regional levels, because it is estimated to be found in

404 fewer than 5 locations within an estimated area of $6,000 \mathrm{~km}^{2}$. Only approximately $9 \%$ of the

405 species' range in Mongolia lies within protected areas, mostly in Mongolian Altay Mountains

406 (i.e. the opposite (north) slope of our study areas) (Terbish, Munkhbayar \& Munkhbaatar, 2006).

407 Little is known about the threats to the adder in both China and Mongolia. Clearly, extensive

408 research is recommended to determine the status and threats of the species, and further to

409 develop management plans in these areas.

\section{Acknowledgement}

411 We are grateful to Zhang Liang for helpful advice on the manuscript. We thank Li Lili, Qi

412 Yingjie, Li Yubing, Li Na, Ji Shengnan, Tao Xiaqiu, and staffs from Kanas Nature Reserve for

assistance during fieldwork. Thanks also to Ulrich Joger and an anonymous reviewer for

insightful comments that improved the manuscript.

\section{References}

Alexander Pyron R, and Burbrink FT. 2009. Lineage diversification in a widespread species: roles for niche divergence and conservatism in the common kingsnake, Lampropeltis getula. Molecular Ecology 18:34433457. DOI: 10.1111/j.1365-294X.2009.04292.x.

Andrén C, and Nilson G. 1981. Reproductive success and risk of predation in normal and melanistic colour morphs of the adder, Vipera berus. Biological Journal of the Linnean Society 15:235-246. DOI: 10.1111/j.10958312.1981.tb00761.x. 
422

423

424

425

426

427

428

429

430

431

432

433

434

435

436

437

438

439

440

441

442

443

444

445

446

447

448

449

450

451

452

453

454

455

456

457

458

459

460

461

462
Bannikov A, Darevsky I, Ishchenko V, Rustamov A, and Szczerbak N. 1977. Guide to Amphibians and Reptiles of the USSR Fauna. Moscow: Prosveshchenie.

Buckland ST, Anderson DR, Burnham KP, Laake JL, Borchers DL, and Thomas L. 2001. Introduction to distance sampling: estimating abundance of biological populations. Oxford, UK: Oxford University Press.

Burbrink FT, Lawson R, and Slowinski JB. 2000. Molecular phylogeography of the North American rat snake (Elaphe obsoleta): a critique of the subspecies concept. Evolution 54:2107-2118. DOI: 10.1111/j.00143820.2000.tb01253.x.

Castella B, Golay J, Monney JC, Golay P, Mebert K, and Dubey S. 2013. Melanism, body condition and elevational distribution in the asp viper. Journal of Zoology 290:273-280. DOI: 10.1111/jzo.12037.

Clusella-Trullas S, van Wyk JH, and Spotila JR. 2007. Thermal melanism in ectotherms. Journal of Thermal Biology 32:235-245. DOI: 10.1016/j.jtherbio.2007.01.013.

Dohm MR, and Garland T. 1993. Quantitative Genetics of Scale Counts in the Garter Snake Thamnophis sirtalis. Copeia 1993:987-1002. DOI: 10.2307/1447076.

Ferchaud A-L, Ursenbacher S, Cheylan M, Luiselli L, Jelić D, Halpern B, Major Á, Kotenko T, Keyan N, Behrooz R, Crnobrnja-Isailović J, Tomović L, Ghira I, loannidis Y, Arnal V, and Montgelard C. 2012. Phylogeography of the Vipera ursinii complex (Viperidae): mitochondrial markers reveal an east-west disjunction in the Palaearctic region. Journal of Biogeography 39:1836-1847. DOI: 10.1111/j.1365-2699.2012.02753.x.

Fornasiero S, Corti C, Luiselli L, and Zuffi MA. 2007. Sexual size dimorphism, morphometry and phenotypic variation in the Whip snake Hierophis viridiflavus from a central Mediterranean area. Revue d'Écologie (la Terre et la Vie) 62:73-85.

Forsman A, and Âs S. 1987. Maintenance of colour polymorphism in adder, Vipera berus, populations: a test of a popular hypothesis. Oikos 50:13-16. DOI: 10.2307/3565396.

Gasc JP, Cabela A, Crnobrnja-Isailovic J, Dolmen D, Grossenbacher K, Haffner P, Lescure J, Martens H, Martínez Rica JP, Maurin H, Oliveira ME, Sofianidou TS, Veith M, and Zuiderwijk A. 1997. Atlas of amphibians and reptiles in Europe. Paris: Societas Europaea Herpetologica \& Museum National d'Histoire Naturelle.

Gvoždík V, Jandzik D, Cordos B, Rehák I, and Kotlík P. 2012. A mitochondrial DNA phylogeny of the endangered vipers of the Vipera ursinii complex. Molecular Phylogenetics and Evolution 62:1019-1024. DOI: 10.1016/j.ympev.2011.12.001.

Hijmans RJ, Cameron SE, Parra JL, Jones PG, and Jarvis A. 2005. Very high resolution interpolated climate surfaces for global land areas. International Journal of Climatology 25:1965-1978. DOI: 10.1002/joc.1276.

Holt RD, and Keitt TH. 2005. Species' borders: a unifying theme in ecology. Oikos 108:3-6. DOI: 10.1111/j.00301299.2005.13145.x.

Joger U, Fritz U, Guicking D, Kalyabina-Hauf S, Nagy ZT, and Wink M. 2007. Phylogeography of western Palaearctic reptiles - Spatial and temporal speciation patterns. Zoologischer Anzeiger 246:293-313. DOI: 10.1016/j.jcz.2007.09.002.

Larkin MA, Blackshields G, Brown N, Chenna R, McGettigan PA, McWilliam H, Valentin F, Wallace IM, Wilm A, and Lopez R. 2007. Clustal W and Clustal X version 2.0. Bioinformatics 23:2947-2948.

Librado P, and Rozas J. 2009. DnaSP v5: a software for comprehensive analysis of DNA polymorphism data. Bioinformatics 25:1451-1452.

Lourdais O, Shine R, Bonnet X, Guillon M, and Naulleau G. 2004. Climate affects offspring phenotypes in a viviparous snake. Oikos 104:551-560. 
463

464

465

466

467

468

469

470

471

472

473

474

475

476

477

478

479

480

481

482

483

484

485

486

487

488

489

490

491

492

493

494

495

496

497

498

499

500

501

502

503

Luiselli L. 1992. Reproductive Success in Melanistic Adders: A New Hypothesis and Some Considerations on Andrén and Nilson's (1981) Suggestions. Oikos 64:601-604. DOI: 10.2307/3545182.

Madsen T, Stille B, and Shine R. 1996. Inbreeding depression in an isolated population of adders Vipera berus. Biological Conservation 75:113-118. DOI: 10.1016/0006-3207(95)00067-4.

Malhotra A, and Thorpe RS. 1997. Microgeographic Variation in Scalation of Anolis oculatus (Dominica, West Indies): A Multivariate Analysis. Herpetologica 53:49-62.

Milto K, and Zinenko O. 2005. Distribution and morphological variability of Vipera berus in Eastern Europe. In: Ananjeva N, and Tsinenko O, editors. Herpetologia Petropolitana Proceedings of the 12th Ordinary General Meeting of the Societas Europaea Herpetologica. Russia, Saint-Petersburg: Russian Academy of Sciences, 64-73.

Monney J-C, Luiselli L, and Capula M. 1995. Correlates of melanism in a population of adders (Vipera berus) from the Swiss Alps and comparisons with other alpine populations. Amphibia-Reptilia 16:323-330. DOI: 10.1163/156853895X00406.

Nilson G, and Andrén C. 2001. The meadow and steppe vipers of Europe and Asia-the Vipera (Acridophaga) ursinii complex. Acta Zoologica Academiae Scientiarum Hungaricae 47:87-267.

Nilson G, Andrén C, and Szyndlar Z. 1994. The systematic position of the Common Adder, Vipera berus (L.)(Reptilia, Viperidae), in North Korea and adjacent regions. Bonner zoologische Beiträge 45:49-56.

Osgood DW. 1978. Effects of temperature on the development of meristic characters in Natrix fasciata. Copeia 1978:33-47.

Phelps T. 2004. Population dynamics and spatial distribution of the adder Vipera berus in southern Dorset, England. Mertensiella 15:241-258.

Posada D, and Crandall KA. 1998. Modeltest: testing the model of DNA substitution. Bioinformatics 14:817-818.

R Core Team. 2013. R: a language and environment for statistical computing. Vienna: R Foundation for Statistical Computing. Available at http://www.R-project.org. Ravkin YS, Bogomolova IN, and Chesnokova SV. 2010. Amphibian and reptile biogeographic regions of Northern Eurasia, mapped separately. Contemporary Problems of Ecology 3:562-571. DOI: 10.1134/s1995425510050103.

Ronquist F, and Huelsenbeck JP. 2003. MrBayes 3: Bayesian phylogenetic inference under mixed models. Bioinformatics 19:1572-1574.

Ruxton GD. 2006. The unequal variance t-test is an underused alternative to Student's t-test and the MannWhitney U test. Behavioral Ecology 17:688-690. DOI: 10.1093/beheco/ark016.

Saint Girons H. 1980. Biogéographie et évolution des vipéres européennes. Compte Rendu Des Séances de la Société de Biogéographie 496:146-172.

Santos X, Vidal-García M, Brito JC, Fahd S, Llorente GA, Martínez-Freiría F, Parellada X, Pleguezuelos JM, and Sillero N. 2014. Phylogeographic and environmental correlates support the cryptic function of the zigzag pattern in a European viper. Evolutionary Ecology 28:611-626. DOI: 10.1007/s10682-014-9699-6.

Schiemenz H. 1995. Die Kreuzotter Spektrum. Heidelberg, Germany: Akademischer Verlag.

Sillero N, Campos J, Bonardi A, Corti C, Creemers R, Crochet P-A, Crnobrnja Isailović J, Denoël M, Ficetola GF, Gonçalves J, Kuzmin S, Lymberakis P, de Pous P, Rodríguez A, Sindaco R, Speybroeck J, Toxopeus B, Vieites DR, and Vences M. 2014. Updated distribution and biogeography of amphibians and reptiles of Europe. Amphibia-Reptilia 35:1-31. DOI: 10.1163/15685381-00002935.

Strugariu A, and Zamfirescu ŞR. 2011. Population characteristics of the adder (Vipera berus berus) in the Northern 
504

505

506

507

508

509

510

511

512

513

514

515

516

517

518

519

520

521

522

523

524

525

526

527

528

529

530

531

532

533

534

535

536

537

538

539

540

541

542

Romanian Carpathians with emphasis on colour polymorphism: is melanism always adaptive in vipers? Animal Biology 61:457-468. DOI: 10.1163/157075511X597601.

Tóth T, and Farkas B. 2004. The Bosnian adder (Vipera berus bosniensis) in Southwestern Hungary. Litteratura Serpentium 24:129-144.

Tamura K, Stecher G, Peterson D, Filipski A, and Kumar S. 2013. MEGA6: Molecular Evolutionary Genetics Analysis Version 6.0. Molecular Biology and Evolution 30:2725-2729. DOI: 10.1093/molbev/mst197.

Terbish K, Munkhbayar K, Clark EL, Munkhbat J, Monks EM, Munkhbaatar M, Baillie JEM, Borkin L, Batsaikhan N, Samiya R, and Semenov DV. 2006. Mongolian Red List of Reptiles and Amphibians. Regional Red List Series. Vol. 5. London: Zoological Society of London.

Terbish K, Munkhbayar K, and Munkhbaatar M. 2006. A guide to the amphibians and reptiles of Mongolia. Ulaanbaatar, Mongolia: Munkhiin Useg Publ.

Thorpe RS, Brown RP, Malhotra A, and Wuster W. 1991. Geographic variation and population systematics: distinguishing between ecogenetics and phylogenetics. Italian Journal of Zoology 58:329-335.

Tuniyev B, Nilson G, and Andrén C. 2010. A new species of viper (Reptilia, Viperidae) from the Altay and Saur Mountains, Kazakhstan. Russian Journal of Herpetology 17:110-120.

Ursenbacher S, Carlsson M, Helfer V, TegelstrÖM H, and Fumagalli L. 2006. Phylogeography and Pleistocene refugia of the adder (Vipera berus) as inferred from mitochondrial DNA sequence data. Molecular Ecology 15:3425-3437. DOI: 10.1111/j.1365-294X.2006.03031.x.

Wares JP. 2014. Mitochondrial cytochrome b sequence data are not an improvement for species identification in scleractinian corals. PeerJ 2:e564. DOI: 10.7717/peerj.564.

Wei W, He Q, Liu M, and Gao W. 2003. Climate change and the desert environment in Junggar Basin, Xinjiang, China. Journal of Desert Research 23:101-105.

Xu C, Li J, Zhao J, Gao S, and Chen Y. 2015. Climate variations in northern Xinjiang of China over the past 50 years under global warming. Quaternary International 358:83-92. DOI: 10.1016/j.quaint.2014.10.025.

Zhang Y. 1999. Zoogeography of China. Beijing: Science Press.

Zhao E, and Adler K. 1993. Herpetology of China. Oxford, Ohio: Society for the Study of Amphibians and Reptiles.

Zhao E. 2006. Snakes of China. Hefei: Anhui Science and Technology Publishing House.

Zhao E, Huang M, and Zong Y. 1998. The fauna of China, reptilia. Beijing: Science Press.

Zhou L, and Shi L. 2015. Amphibian and reptilian distribution patterns in the transitional zone between the EuroSiberian and Central Asia Subrealms. Journal of Arid Land 7:555-565. DOI: 10.1007/s40333-015-0124-y.

Zinenko O, Stümpel N, Mazanaeva L, Bakiev A, Shiryaev K, Pavlov A, Kotenko T, Kukushkin O, Chikin Y, Duisebayeva T, Nilson G, Orlov NL, Tuniyev S, Ananjeva NB, Murphy RW, and Joger U. 2015. Mitochondrial phylogeny shows multiple independent ecological transitions and northern dispersion despite of Pleistocene glaciations in meadow and steppe vipers (Vipera ursinii and Vipera renardi). Molecular Phylogenetics and Evolution 84:85-100. DOI: 10.1016/j.ympev.2014.12.005.

Zinenko O, Jurcanu V, and Strugariu A. 2010. Distribution and morphological variation of Vipera berus nikolskii Vedmederja, Grubant et Rudaeva, 1986 in Western Ukraine, The Republic of Moldova and Romania. Amphibia-Reptilia 31:51-67. DOI: 10.1163/156853810790457885. 


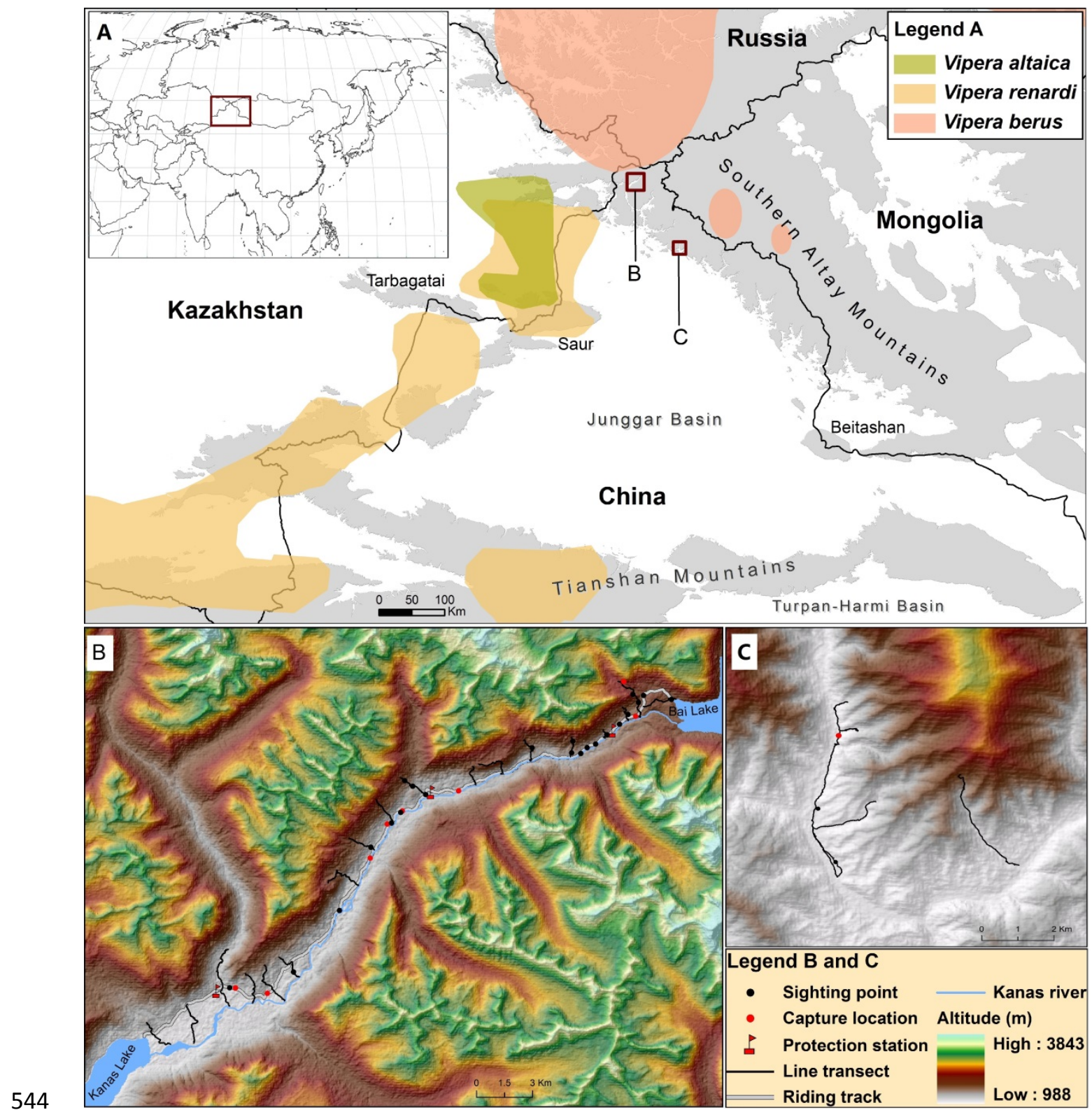

545 Figure 1 Map describing the distribution of $V$. berus and its relatives ( $V$. renardi and $V$. altaica)

546 in Southern Altay Mountains (A). The detailed map of survey locations and field investigations

547 is shown at Kanas river valley (B) and Daxiaodonggou Forested Area (C). The different

548 distribution ranges are displayed following Nilson, Andrén \& Szyndlar (1994), Nilson \& Andrén

549 (2001), Terbish et al. (2006), Ursenbacher et al. (2006), Tuniyev, Nilson \& Andrén (2010), and

550 Gvoždík et al. (2012). 

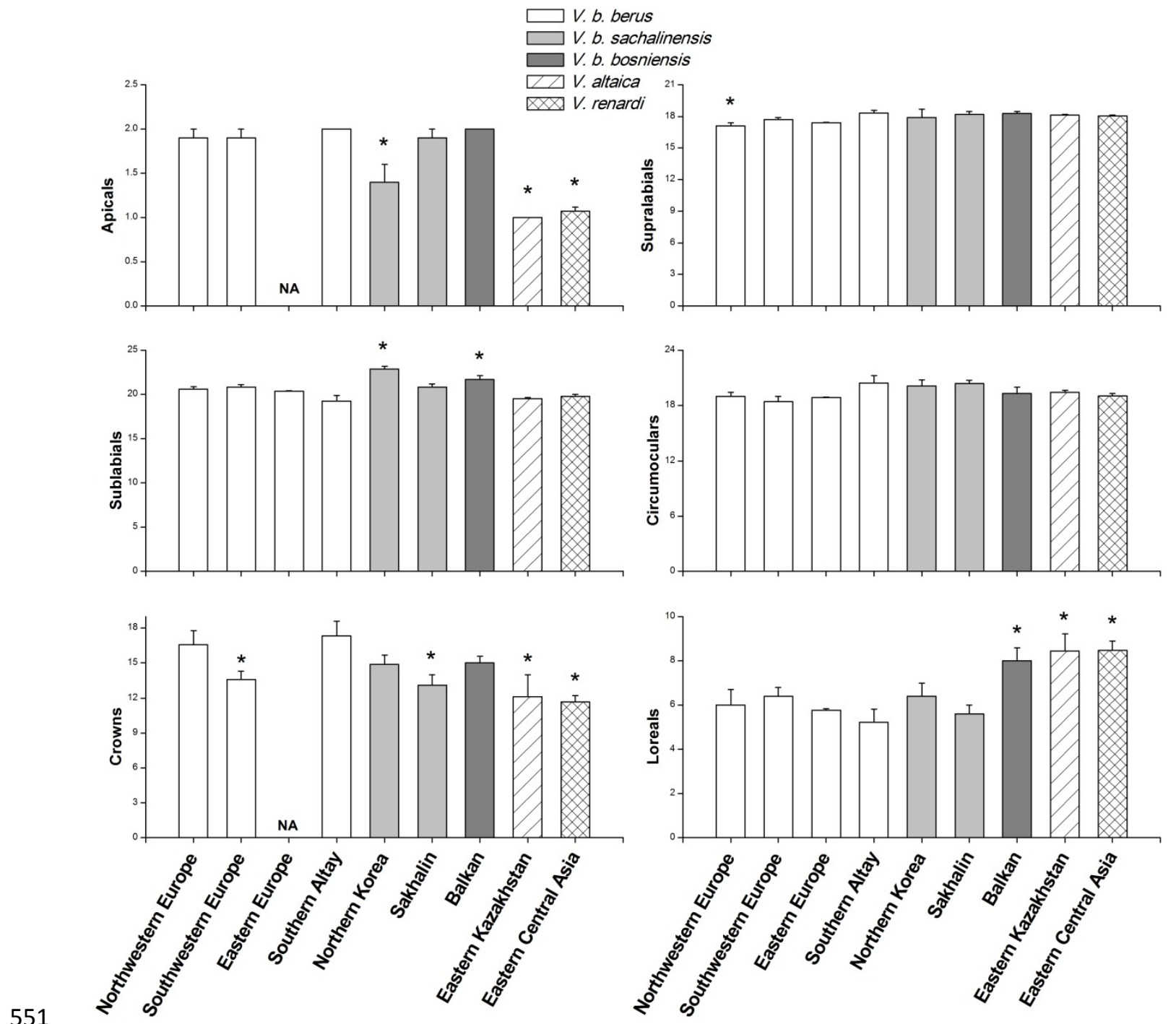

Figure 2 Comparisons of morphological characteristics of $V$. berus and related species.

Asterisk $\left(^{*}\right)$ represents a significant difference between our specimens from Southern Altay

Mountains and other taxa from different geographical regions (multiple comparison tests, $P<$

0.05). Data on the number of apicals and crowns in the adder population from Eastern Europe were not available (NA). The source and sample sizes (n) of the morphological data of different taxa are as follows: V. b. berus from Northwestern and Southwestern Europe (n=19 and 14, respectively; Nilson, Andrén \& Szyndlar, 1994), Eastern Europe (n=45; Milto \& Zinenko, 
559 2005), and Southern Altay ( $=9$; this study, voucher numbers listed in Supplemental Raw Data);

560 V. b. sachalinensis from Northern Korea and Sakhalin ( $\mathrm{n}=12$ and 10, respectively; Nilson,

561 Andrén \& Szyndlar, 1994); V. b. bosniensis from Balkan (n=15; Nilson, Andrén \& Szyndlar,

562 1994); V. altaica from Eastern Kazakhstan (n = 38; Tuniyev, Nilson \& Andrén, 2010); $V$.

563 renardi from Eastern Central Asia (n = 30; Nilson \& Andrén, 2001; Tuniyev, Nilson \& Andrén,

564 2010).

565

566

567

568

569

570

571

572

573

574 


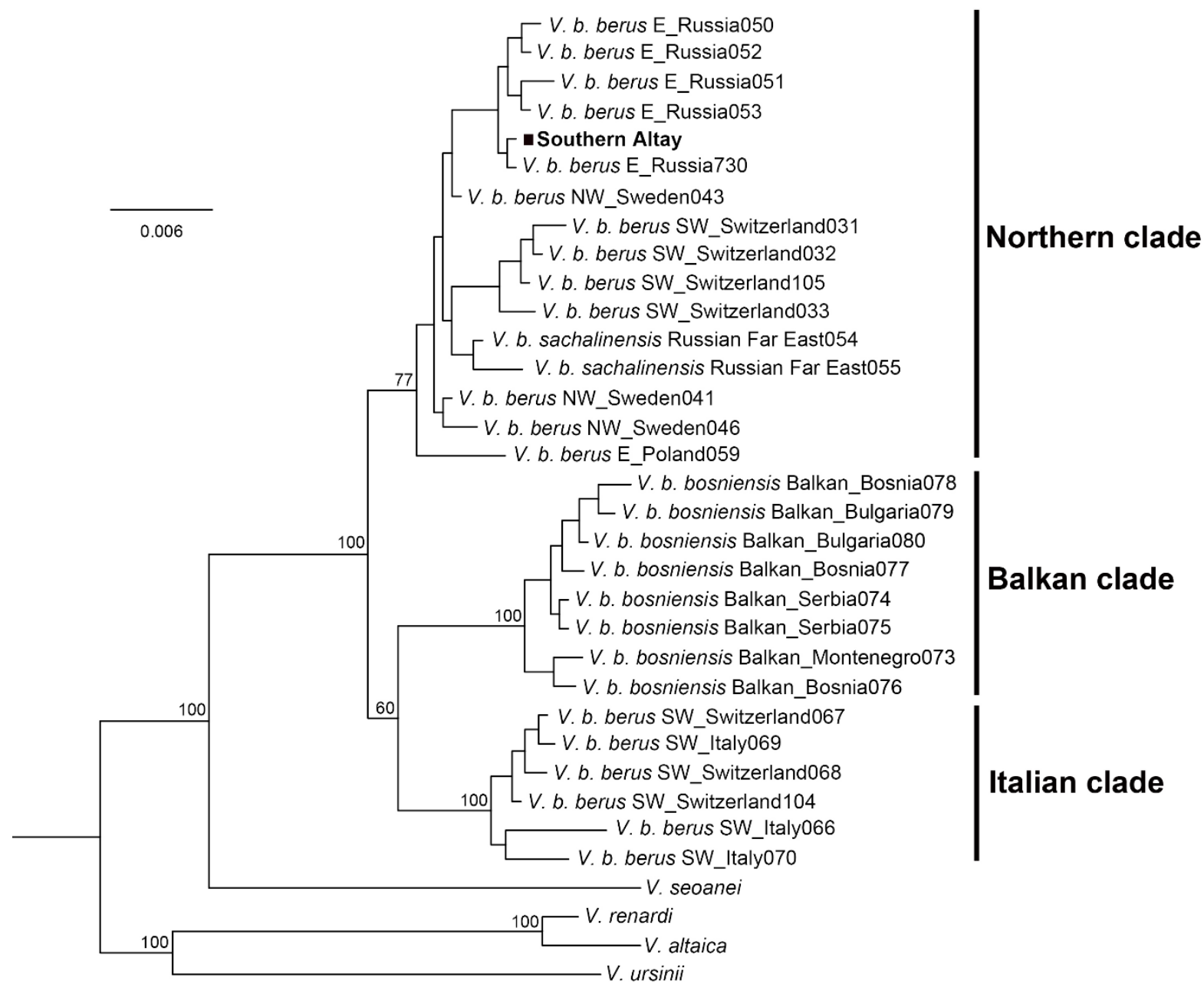

575

576 Figure 3 Phylogenetic tree of cytochrome $b$ obtained from Bayesian analysis. Bayesian posterior

577 probability is shown for the main nodes. The geographic origin of each haplotype is indicated (E,

578 Eastern Europe; SW, Southwestern Europe; NW, Northwestern Europe). The samples from

579 Southern Altay Mountains are highlighted by the black block. See Supplemental Table S1 for

580 sample codes, locations and accession numbers. 
582 Table 1 Comparisons of ventrals and subcaudals of $V$. berus from different geographical regions.

583 The source of the morphological data of different taxa is shown in Fig. 2.

\begin{tabular}{|c|c|c|c|c|c|c|c|}
\hline \multirow{2}{*}{ Taxon } & \multirow{2}{*}{ Location } & \multicolumn{3}{|c|}{ Males } & \multicolumn{3}{|c|}{ Females } \\
\hline & & $\mathrm{N}$ & Ventrals & Subcaudals & $\mathrm{N}$ & Ventrals & Subcaudals \\
\hline \multirow[t]{4}{*}{$V . b$. berus } & Northwestern Europe & 10 & $140.7 \pm 0.9$ & $38.0 \pm 0.6$ & 4 & $145.5 \pm 3.2$ & $30.3 \pm 0.8$ \\
\hline & Southwestern Europe & 11 & $139.5 \pm 1.2$ & $34.6 \pm 1.4$ & 3 & $141.3 \pm 1.5$ & $25.3 \pm 1.5$ \\
\hline & Eastern Europe & 22 & $144.5 \pm 0.4$ & $38.9 \pm 0.5$ & 23 & $148.6 \pm 0.6$ & $31.1 \pm 0.4$ \\
\hline & Southern Altay & 3 & $143.0 \pm 1.7$ & $38.7 \pm 0.9$ & 6 & $146.2 \pm 1.1$ & $33.7 \pm 1.1$ \\
\hline \multirow{2}{*}{$\begin{array}{l}V . b . \\
\text { sachalinensis }\end{array}$} & Northern Korea & 4 & $144.7 \pm 1.3$ & $35.2 \pm 1.1$ & 6 & $151.8 \pm 0.9$ & $31.2 \pm 0.9$ \\
\hline & Sakhalin & 7 & $146.9 \pm 1.1$ & $37.3 \pm 0.9$ & 3 & $154.7 \pm 0.9$ & $28.3 \pm 0.7$ \\
\hline V. b. bosniensis & Balkan & 9 & $142.1 \pm 0.9$ & $37.1 \pm 1.4$ & 6 & $143.7 \pm 1.9$ & $30.2 \pm 0.7$ \\
\hline V. altaica & Eastern Kazakhstan & 16 & & $35.4 \pm 0.3$ & 21 & & $27.2 \pm 0.3$ \\
\hline
\end{tabular}

584 Notes: The collected specimens in this study are shown in bold. 
587 Table 2 Genetic distance of Vipera berus among different geographic populations.

\begin{tabular}{lllll}
\hline & Southern Altay & Northern clade & Far East & Italian clade \\
\hline Northern clade & $0.003 \pm 0.001$ & & & \\
Far East & $0.005 \pm 0.002$ & $0.005 \pm 0.002$ & & \\
Italian clade & $0.014 \pm 0.004$ & $0.014 \pm 0.003$ & $0.014 \pm 0.004$ & \\
Balkan clade & $0.014 \pm 0.004$ & $0.014 \pm 0.004$ & $0.014 \pm 0.004$ & $0.017 \pm 0.004$ \\
\hline
\end{tabular}

588 Notes: Sequences are grouped together based on the phylogenetic results but samples of

589 Southern Altay Mountains and Russia Far East are treated as two separated groups. 